\title{
HABITUS DAN ARENA DALAM NOVEL TAMAN API KARYA YONATHAN RAHARDJO
}

\author{
Everhard Markiano Solissa \\ Universitas Pattimura \\ Mahasiswa S-3 Pendidikan Bahasa dan Sastra Universitas Negeri Surabaya \\ eversolissa@yahoo.com
}

\begin{abstract}
ABSTRAK
Karya sastra lahir dari latar belakang dan dorongan dasar manusia untuk mengungkapkan eksisitensi dirinya. Karya sastra lahir bukan dari ruang kosong melompong, tetapi dari sebuah interaksi dengan realitas kehidupan manusia. Salah satu realitas dalam kehidupan dunia kontemporer sekarang ini adalah adanya krisis identitas dan subjektivitas. Tujuan penelitian ini adalah menemukan dan mendeskripsikan habitus dan arena dalam novel Taman Api karya Yonathan Rahrdjo. Data dikumpulkan dengan teknik pustaka. Dengan menggunakan teori medan sastra Pierre Bourdieu, ditemukan bahwa (1) novel Taman Api menggambarkan bentuk habitus atau cara pandang seseorang dalam menentukan tindakan. Habitus agen terus bergerak dari waktu ke waktu. Pergerakan itu diakibatkan oleh pengalaman, didikan, atau bahkan pergaulan; (2) arena dalam novel Taman Api berupa arena kedokteran yang dianggap arena orang berkelas. Namun demikian, dalam arena ini agen-agenya tidak mencerminkan akhlak yang baik. Arena berikutnya adalah arena bisnis di mana setiap agen berupaya menjalankan fungsi dengan sebaik-baiknya agar jaringan yang dibangun tetap bertahan untuk kepentingan bersama yaitu saling menguntungkan. Arena yang terakhir adalah arena waria. Setiap agen dalam arena ini dianggap perusak tatanan moralitas, dan sering menjadi sasaran kekerasan penguasa.
\end{abstract}

Kata Kunci: karya sastra, medan sastra, agen, habitus, arena

\section{ABSTRACT}

Literary works are born of the background and the basic human impetus to express their existence. They are not born of an empty space, but of an interaction with the reality of human life. One of the contemporary world life realities today is the existence of an identity and subjectivity crisis. The objectives of this research are to find and to describe the habitus and arena in the novel Taman Api by Yonantha Rahardjo. The data are collected by the library techniques. By using literary fields theory of Pierre Bourdieu, some issues are found. Those are (1) the novel Taman Api depicts the form of habitus or someone's perspective in determining the action. Habitus of the agent keeps moving from time to time. The movement is caused by experiences, education, or even intercommunication; (2) the arena in the novel Taman Api is in the form of medic which is considered as the arena of the elite. Nevertheless, in this arena, the agents do not reflect good morals. 
Another arena is business where each agent makes serious efforts to perform his function as well as possible in order that networks remain for the mutual benefit. The last arena is a transvestite. Each agent, in this arena, is considered as a destroyer of the order of morality and is often subjected to the violence of the ruler.

Keywords: literary works, literary fields, agent, habitus, arena

\section{PENDAHULUAN}

Karya sastra lahir dari pengekspresian endapan pengalaman yang telah ada dalam jiwa pengarang secara mendalam melalui proses imajinasi (Nurgiyantoro, 2010:57). Karya sastra lahir dari latar belakang dan dorongan dasar manusia untuk mengungkapkan eksisitensi dirinya. Sebuah karya sastra dipersepsikan sebagai ungkapan realitas kehidupan dan konteks penyajiannya disusun secara terstruktur, menarik, serta menggunakan media bahasa berupa teks.

Salah satu realitas dalam kehidupan dunia kontemporer sekarang ini adalah adanya krisis identitas dan subjektivitas. Krisis ditandai dengan upaya pencarian identitas berupa operasi wajah, pembuatan tato, pemakaian anting, rambut di-rebounding, bahkan sampai pada operasi kelamin.

Hal-hal tersebut menjadi objek yang menarik untuk diperbincangkan bukan saja dalam dialog-dialog, seminar-seminar, tetapi juga dalam karya sastra. Salah satunya adalah masalah transgender. Transgender adalah istilah yang digunakan untuk mendeskripsikan orang yang melakukan, merasa, berpikir atau terlihat berbeda dari jenis kelamin yang sejak lahir mereka dapatkan, atau jelasnya bisa dikatakan sebagai lelaki yang mengubah dirinya menjadi perempuan atau sebaliknya.

Novel Taman Api yang ditulis oleh Yonathan Rahardjo adalah salah satu novel yang mengangkat sisi lain kaum transgender (kaum waria). Novel ini merupakan novel kedua yang ditulis oleh Yonathan Rahadjo. Ia adalah seorang dokter hewan yang begitu tertarik untuk menceritakan hal-hal yang tidak biasa dalam masyarakat. Yonathan Rahardjo adalah salah satu pemenang sayembara novel Dewan Kesenian Jakarta 2006. Ia adalah salah satu penulis Indonesia yang terpilih mengikuti Ubud Writers and Readers Festival (UWRF) tahun 2009 di Bali.

Kisah yang ditulis oleh Yonathan Rahardjo dalam novel Taman Api akan dikaji dengan teori medan sastra. Teori medan sastra memandang masyarakat sebagai penghuni blok-blok atau wilayahwilayah yang dibuat berdasarkan persamaan pola pikir, presepsi dan pengalaman. Dalam teori ini setiap individu akan ditempatkan atau memiliki wilayah masing-masing sesuai dengan kemampuannya dalam berpikir dan beradaptasi.

Ada dua macam konsep yang ditawarkan oleh Pierre Bourdiue dalam teori ini yaitu habitus dan arena, konsep yang saling mendukung dan saling berkaitan. Dapat dijelaskan dengan singkat bahwa jika seseorang memiliki pola pikir atau pandangan yang mengstigma kaum waria sebagai pendosa karena Tuhan hanya 
menciptakan laki-laki dan perempuan, maka orang tersebut dapat hidup dalam arena atau wilayah kaum agamis yang dominan.

Menurut Fashri (2014:99), habitus dapat dirumuskan sebagai sebuah struktur sosial yang dibatinkan yang diwujudkan. Atau dengan kata lain habitus adalah hasil pengalaman pribadi seseorang tentang nilai-nilai sosial, terstuktur dan berlangsung lama, mengendap dalam pikiran dan menjadi sebuah cara pandang atau pola pikir.

Habitus seseorang begitu kuat, sampai mempengaruhi perkembangan pemikirannya. Habitus yang sudah begitu kuat tertanam serta mengendap menjadi perilaku fisik disebutnya sebagai Hexis. Hexis sendiri dapat mempengaruhi pola pemikiran seseorang sehingga dapat membuatnya menjadi pemikir yang kurang kritis karena menilai sesuatu berdasarkan pengalaman dan pola pandangnya saja (Wattimena 2012:2)

Bordieu memaparkan bahwa habitus seseorang dipengaruhi oleh beberapa hal, antara lain:

\section{1) Kapital/Modal}

Kapital adalah modal yang memungkinkan kita untuk mendapatkan kesempatan-kesempatan di dalam hidup. Ada banyak jenis kapital, seperti kapital intelektual (pendidikan), kapital ekonomi (uang), dan kapital budaya (latar belakang dan jaringan). Kapital bisa diperoleh, jika orang memiliki habitus yang tepat dalam hidupnya.

\section{2) Kelas}

Bourdieu (2015:ix) mengemukaan bahwa sistem dominasi dalam sebuah arena telah mengklasifikasikan agen dalam kelas-kelas tertentu. Setiap kelas memiliki sikap, selera, kebiasaan, perilaku atau bahkan modal yang berbeda.

Bourdieu membedakan kelas menjadi tiga. Pembedaan ini sekali lagi didasarkan pada faktor pemilihan modal tadi. Pertama, kelas dominan (Bourdieu 2015:216). Kelas dominan adalah pemilikan modal yang cukup besar. Kedua, kelas borjouis kecil (Bourdieu, 2015:217), yaitu mereka memiliki keinginan untuk menaiki tangga sosial, akan tetapi mereka menempati kelas menengah dalam struktur masyarakat. Ketiga, kelas popular/terdominasi (Bourdieu, 2015:216). Kelas ini merupakan kelas yang hampir tidak memiliki modal, baik modal ekonomi, modal budaya maupun modal simbolik.

\section{3) Dominasi Simbolik}

Dominasi simbolik adalah penindasan dengan menggunakan simbol-simbol. Penindasan ini tidak dirasakan sebagai penindasan, tetapi sebagai sesuatu yang secara normal perlu dilakukan. Artinya, penindasan tersebut telah mendapatkan persetujuan dari pihak yang ditindas itu sendiri (Bourdieu dalam Wattimena, 2012:7). Menurut Bourdieu, kekerasan berada dalam lingkup kekuasaan. 


\section{4) Pembedaan}

Bourdieu (Wattimena, 2012:5) merumuskan konsep pembedaan (distinction) sebagai tindakan membedakan diri yang dilakukan oleh seseorang untuk menunjukkan kelasnya dalam masyarakat. Biasanya, pembedaan dilakukan oleh kelas menengah ke atas untuk menunjukkan statusnya yang khas dibandingkan dengan kelas ekonomi yang lebih rendah.

\section{5) Perubahan Sosial dan Kebebasan}

Perubahan sosial bisa dilakukan, jika seseorang memiliki kapital yang mendukung serta dapat memilih arena yang tepat untuk menempatkan dirinya agar orang tersebut mendapatkan habitus yang baik pula (Wattimena, 2012:8). Perubahan sosial hanya mungkin, jika manusia bukan merupakan "budak" dari sistem sosial yang mengitarinya. Dengan kata lain, perubahan sosial hanya mungkin, jika ada kebebasan. Bagi Bourdieu, kebebasan adalah suatu bentuk improvisasi yang menghasilkan variasi. Artinya, kebebasan adalah perubahan yang dapat menciptakan sesuatu.

Bourdieu (2015:213) mendefinisikan arena sebagai sebuah semesta sosial terpisah yang memiliki hukum-hukum keberfungsiannya sendiri. Dengan demikian dapat dikatakan bahwa ada berbagai macam arena seperti pendidikan, arena bisnis, arena seniman, dan arena politik. Arena pendidikan memiliki aturannya sendiri.

Fashri (2014:106) menjelaskan bahwa arena adalah ruang yang di dalamnya terdapat upaya perjuangan untuk memperebutkan sumber daya (modal) dan juga untuk memperoleh akses tertentu yang dekat dekan kekuasaan. Dengan demikian, dalam arena setiap individu atau kelompok digiring untuk merancang strategi dan menggunakan strategi itu untuk meraih posisi. Persaingan menjadi hal yang lumrah, karena setiap strategi telah memperhitungkan hal tersebut. Persaingan yang sehat akan menghasilkan sesuatu yang baik, namun persaingan yang tidak sehat akan menimbulkan konflik.

Konsep arena ikut mendukung habitus seseorang (Wattimena, 2012:3). Artinya, arena dan habitus sangat terikat erat. Untuk bisa berhasil dalam salah satu arena hidup, orang perlu mempunyai habitus yang tepat untuk arena itu. Jika ia tidak memiliki habitus yang tepat untuk satu arena, maka ia, kemungkinan besar, akan gagal dalam arena yang telah ia pilih tersebut.

METODE

Penelitian ini termasuk penelitian kualitatif, yaitu penelitian yang mengungkap gejala atau fenomena secara menyeluruh dan kontekstual tentang topik yang diteliti (Moleong, 2008:6). Penelitian ini bersifat deskriptif yaitu memberikan gambaran secara jelas tentang habitus dan arena dalam novel Taman Api karya Yonathan Rahardjo.

Data diperoleh melalui teknik pustaka, yaitu dengan mempergunakan sumber-sumber tertulis untuk memperoleh data. 
Dalam teknik pustaka, peneliti sebagai instrumen kunci melakukan pembacaan dan pencatatan secara cermat, terarah, dan teliti terhadap sumber data yakni novel Taman Api. Pada saat melakukan pembacaan, peneliti sekaligus mencatat bagian-bagian novel, dalam hal ini kata dan kalimat yang berkaitan dengan tujuan penelitian. Pembacaan dilakukan secara berulang-ulang sehingga data yang dikumpulkan lebih akurat.

Analisis data penelitian ini menggunakan model spiral yang dikemukakan oleh Creswell (2014:254). Dengan demikian, proses mengidentifikasi agen, mengidentifikasi watak tokoh, mengidentifikasi perbuatan/tindakan agen, dan mengidentifikasi habitus dan arena dilakukan dengan cermat dan berulang-ulang untuk memperoleh hasil yang memadai.

\section{PEMBAHASAN Habitus dalam Novel Taman Api}

Tari adalah seorang tokoh pria yang diceritakan memiliki kelainan seksual sejak kecil yang membuatnya berbeda dari kaumnya saat itu. Dia kemudian bertumbuh dewasa dengan kelainan yang membuatnya sulit beradaptasi dengan lingkungannya. Penerimaan yang tidak begitu menyenangkan dari masyarakat sekitar membuatnya menjadi semakin yakin bahwa dia adalah sosok wanita yang terkungkung dalam tubuh seorang pria. Dia tidak mempedulikan masyarakat sekitarnya bahkan dia merasa nyaman hidup sebagai pria berperilaku ganda. Karena adanya dorongan dari dalam dirinya hingga dia menetapkan pilihannya untuk benar-benar meninggalkan jati dirinya sebagai seorang pria dan mengikuti kata hatinya yang cenderung menerima kenyataan sosoknya sebagai wanita. Nona Tari kemudian mengambil pilihan untuk mengubah bentuk fisiknya menjadi seorang wanita tulen dengan sedikit perubahan pada tubuhnya.

Pemikiran yang terkonsep dengan baik ini membuatnya menentukan pilihan hidup yang sulit ketika dia memasuki usia dewasa. Bagi sebagian orang, menentukan pilihan dalam hidup adalah sebuah pekerjaan yang tidak mudah apalagi harus menentukan pilihan-pilihan yang semuanya adalah baik adanya. Begitu pula dengan tokoh Nona Tari. Dia harus mengambil keputusan untuk menjadikan sosok dirinya sebagai seorang pria atau seorang wanita.

Pemikiran dan pengalaman yang Nona Tari dapatkan dari masa kecil hingga dewasa membuatnya harus bergulat hebat dengan dirinya untuk menentukan jati dirinya yang sebenarnya. Nona Tari memilih menjadi seorang wanita karena bagi dirinya dia memang terlahir dengan jiwa seorang wanita hanya saja terjebak dalam tubuh seorang pria. Pada masa dewasa Nona Tari memutuskan hal tersulit dalam hidupnya untuk mengakhiri kodratnya sebagai pria yang diciptakan Tuhan, atau menyenangkan dirinya yang selama ini merasa asing dalam tubuh seorang pria untuk menjadi seorang wanita. Nona Tari memilih mengubah dirinya.

Masalah kegamangan identitas mulai dirasakan oleh tokoh Nona Tari di dalam cerita ini, dia merasa bahwa dirinya yang 
merupakan sosok pria harus dapat diubah menjadi sosok wanita yang selama ini diharapkannya dari dirinya sendiri. Menjadi sebagai seorang wanita. Hal tersebut tampak dalam kutipan berikut.

"Wanita itu 'kan cuma pake susu saja, ya untung-untung kalau susunya montok. Lebih-lebih yang saya tahu cuma bukit kecil saja, dok. Jadi perempuan itu gampang kan dok” (Rahardjo, 2011:3).

Nona Tari memilih menjadi seorang wanita dengan melakukan beberapa perubahan pada tubuhnya sendiri. Dalam pikirannya dia bukanlah seorang pria namun dia hanya terjebak dalam tubuh pria. Untuk itu, dia harus mengakhiri kenyataan itu agar sesuai dengan harapan yang digambarkannya selama ini di dalam pikirannya. Hal tersebut tampak dalam data berikut.

“Coba turuti perintah saya ...” kata dokter saat malam itu, diturutinya dengan penuh patuh, sambil mengingat kata dokter yang cukup menghibur. "Nanti kalau payudara sudah besar sesuai keinginan dan penggunaan pil hormon esterogen dihentikan, dengan sendirinya alat kelamin utama akan normal kembali, “ujar dokter. (Rahardjo, 2011:20).

Namun, masalah kembali muncul ketika dia menyadari bahwa dia memiliki organ kelamin yang tidak dapat terbantahkan adalah penis. Rasa bersalahnya pun muncul ketika dia temukan bahwa akibat pengoperasian payudaranya, organ kelamin utamanya sudah tidak berfungsi dengan baik. Pemikirannya menjadi seorang wanita kemudian sedikit tergoyahkan dengan rasa cemasnya terhadap kurang berfungsinya kelamin utamanya. Di sini harapannya untuk menyamakan diri dengan kaum wanita menjadi sedikit diragukan.

Nona Tari kemudian menyadari bahwa tujuannya dari dulu adalah menyamai dirinya dengan sosok yang disebut wanita itu. Nona Tari kemudian mencoba menindaklanjuti keinginannya yang besar itu untuk menjadikan dirinya sebagai wanita yang utuh. Dia memilih membentuk organ kelamin wanita di antara kedua pahanya. Hal itu tampak pada data berikut.

Namun setelah sekian lama hidup dengan alat kelamin utama laki-laki dan alat kelamin sekunder perempuan, ia mulai merasa dirinya seperti monster. Tumbuh perasaan tak nyaman. Maka, kini saatnya mewujudkan semua impian. Sudah waktunya dokter menganggap layak keberadaanya sebagai perempuan, dan setuju tindakan operasi kelamin terhadapnya (Rahardjo, 2011: 9).

Pemikirannya yang terstruktur sejak kecil akibat keganjilan pada dirinya membentuk pribadinya menjadi lebih berani untuk melakukan hal tersulit dalam hidupnya. Dia kini sudah memiliki sebuah vagina yang artinya dirinya kini sudah dapat disebut sebagai seorang wanita. 
Pergerakan habitus nona Tari dapat divisualkan sebagai berikut.

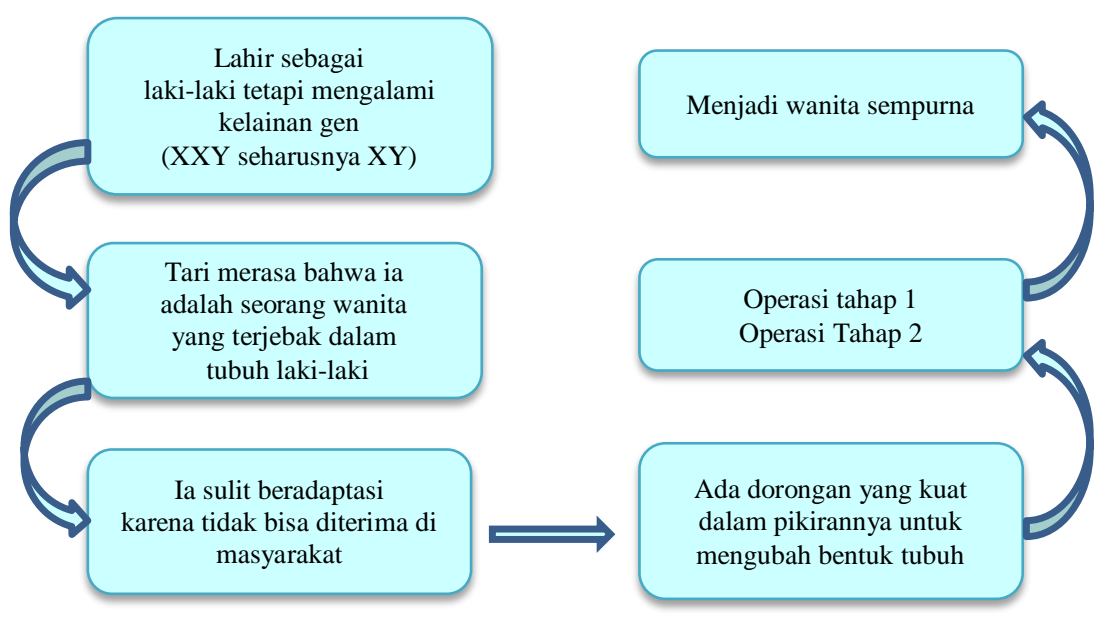

Gambar 1. Pergerakan Habitus “Nona” Tari

\section{Arena dalam Novel Taman Api}

Dalam novel Taman Api, diceritakan bahwa tokoh Nona Tari menemukan wilayah hidup (arena) yang menyenangkan yang menurutnya adalah tempat dirinya tercipta. Arena yang dimaksud adalah kehidupan yang tergolong dalam kelas dominan, kelompok orang bermodal yang membedakan kelasnya dari kelompok yang lain. Hal tersebut tampak pada kutipan berikut.

“Sangat menyenangkan menjadi seorang putri. Itulah aku yang kali ini memakai gaun merah tua. Dalam kerumunan para hadirin di galeri megah bergengsi, ia lintasi para hadirin yang sebagian melihat-lihat lukisan-lukisan yang tergantung di dinding galeri “ (Rahardjo, 2011:13).

Hal tersebut menunjukkan bahwa arena bisnis dalam kelas dominan yang telah menjadi arena kehidupan nona Tari adalah sebuah arena kelas elite. Yang dapat memasuki wilayah ini adalah mereka yang punya modal besar, ditandai dengan pakaian yang mahal buatan luar negeri, asesoris (tas, anting, dll) dengan merek terkenal, mobil dengan lebel kelas atas.

Arena kehidupan yang dipilih nona Tari mengharuskan ia berlomba, berjuang agar dapat tetap bertahan dan menang dapam arena itu. Karena itu, Nona Tari harus memiliki intelektual sebagai modal (kapital). Nona Tari memiliki hal ini, Dia memiliki intelektual di atas rata-rata yang menurut beberapa orang lebih dari kaum waria yang lainnya. Hal tersebut tampak pada data berikut.

Oke Tari. Aku minta kamu menjadi manajer dalam bisnis yang kupimpin”

"Bisnis dengan Mister Patrick untuk memasok kaum waria ke negeri canggih ya Mas?”

"Tepat, kamu cerdas Tari, namun hanya waria-waria unggulan sajalah yang kita kirimkan karena mereka akan 
menjadi duta negara kita. Jangan sampai mempermalukan bangsa”

"Kenapa harus aku, Mas?”

"Karena hanya kamulah yang memiliki intelektual yang tinggi di antara teman-teman sesamamu” (Rahardjo, 2011:164).

Tokoh Tari dalam novel Taman Api berupaya menjadi seseorang yang dapat dipandang sebagai seorang wanita bukan lagi sebagi kaum waria. Dia berupaya membentuk kepribadiannya menjadi wanita pintar yang berintelektual sehingga dapat berinteraksi baik dengan wanita-wanita lain dalam kaum dominan, bahkan dengan kepintarannnya Tari menjadi sosok yang dihargai dalam pandangan kaum dominan.

Untuk hidup di wilayah ini, Nona Tari mesti memiliki kondisi ekonomi yang mapan. Karena dengan modal uang Nona Tari dapat menjadikan dirinya sebagai salah satu anggota dari arena yang diinginkannya ini. Hal itu tampak pada kutipan berikut.

Sedan ungu melintasi jalan-jalan yang nyaris kosong, seakan pengendara sedan adalah pemilik ibu kota yang megah penuh kerlip emas lampu pada malam hitam. 'Aku beruntung bisa hidup nyaman...' waria Tari yang di dalam mobil sedan mengatakan pada diri sendiri. Pada malam berlangit biru, sedan ungu itu masuk kehalaman sebuah rumah megah. Begitu Tari si pengendara sedan itu masuk ke rumah tersebut, malam betul-betul menjadi miliknya (Rahardjo, 2011:40—41)

Nona Tari paham betul untuk menjadi seseorang yang terpandang dia harus memiliki uang yang cukup agar dapat mengubah dirinya. Dengan menggunakan barang mahal Nona Tari percaya dia sanggup diterima dalam kaum dominan yang selama ini dianggapnya sebagai kaum berkelas.

Bukan hanya modal uang yang harus Nona Tari penuhi agar dapat menempati wilayah kaum wanita, namun dia harus mampu menjalin kerja sama yang baik (modal jaringan) dengan agen-agen dalam wilayah ini yang menduduki posisi-posisi penting. Hal tersebut dapat dilihat ada kutipan berikut.

"Pembawa acara memulai pembahasan tentang perubahan jenis kelamin bintang waria terkenal, Tari, yang telah menjalani operasi. Tari didampingi oleh beberapa koleganya yang memang terpandang di masyarakat, dia hadirkan dokter Ranto, seorang ahli agama dan Bapak Lazuardi seorang petinggi polisi” (Rahardjo, 2011: 85)

Nona Tari mengerti bahwa kaum waria dalam pandangan masyarakat luas adalah kelompok masyarakat kelas dua yang kurang terpandang dan kadang tidak dipandang dalam masyarakat. 
Untuk itu, dia harus menjalin kerja sama yang baik dengan orangorang kelas atas yaitu kaum dominan. Data berikut ini menunjukkan hal tersebut.

"Tari, sang empunya pikiran, berjalan berlenggok melintas pada keramaian pesta malam. Dalam kerumunan orang yang hadiri pembukaan galeri lukisan itu, Tari tampak sangat cantik dan menarik (Rahardjo, 2011:13).

Bagi Nona Tari untuk menjadi sama dengan anggota kolektif arena kaum dominan maka dirinya harus banyak berkecimpun dalam acara-acara besar yang berkelas yang dibuat oleh kaum dominan. Karena ketika dia mengikuti acara-acara tersebut dia sudah dapat dikatakan layak untuk bergabung dalam arena tersebut.

Nona Tari menyadari jauh lebih baik dan akan sangat gampang untuk menjadi agen dari kaum wanita dan bahkan diakui sebagai seorang wanita jika dia menikah dengan seorang pria. Itu berarti dia memang sudah layak disebut sebagai wanita. Hal tersebut dapat dilihat pada dialog Tari dan dokter Ranto.

"Sebab aku ingin memilikimu, Tari”

"Kan Mas sudah memilikiku,"

"Maksudku memperisterimu,"

Tari hanya tersipu malu mendengar ucapan dokter Ranto

(Rahardjo, 2011:166)

Impian terbesar dalam hidup nona Tari adalah menjadi wanita sempurna, yaitu menikah. Sebab percuma semua hal yang ia perjuangkan jika impiannya tidak tercapai.

Arena dalam Novel Taman Api dapat divisualkan visual sebagai berikut.

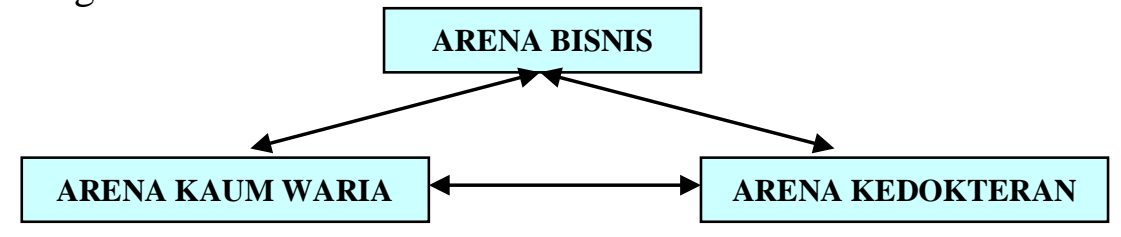

Gambar 2. Arena dalam Novel Taman Api

Arena bisnis ditempati oleh agen-agen seperti Mr. Patric, Dokter Ranto, Nona Tari. Dalam arena ini agen-agen melaksanakan fungsinya dengan baik agar jaringan yang dibangun tetap bertahan untuk kepentingan bersama. Bisnis yang dijalani oleh ketiga agen ini adalah membawa waria dari negeri tanah air ke negeri canggih untuk mengikuti kontes waria tingkat dunia. Tokoh Tari dipercaya sebagai manager dalam bisnis ini. Ini menunjukkan bahwa tokoh Tari berhasil masuk dalam arena kelas dominan dengan modal intelektual dan modal kekayaan.

Arena yang kedua adalah arena kaum waria. Arena ini ditempati oleh agen Riris, Juli, Yanti dll. Dalam arena ini, para 
agen tidak mendapat kepastian hukum karena masalah jenis kelamin yang tidak jelas. Dari segi agama, para agen dalam arena ini dianggap sebagai pendosa sehingga mereka selalu dikucilkan bahkan mendapat kekeran fisik dari agen-agen pemerintah (satpol pramong praja). Wujud arena kaum waria adalah tempat tempat kos di wilayah pinggiran, taman-taman kota, rel kereta api, dan pinggiran jalan. Arena kaum waria adalah arena penuh perjuangan, tidak mengenakkan, sebuah arena yang tidak diidam-idamkan oleh siapa pun kecuali mereka yang habitusnya telah dibentuk untuk itu.

Arena yang terakhir adalah arena kedokteran yang ditempati oleh agen dokter Ranto, dokter Sahrul, dan dokter Hendri. Dalam arena ini para agen dihormati karena profesi ini dianggap sebagai malaikat penolong bagi mereka yang ingin melakukan operasi kelamin. Namun demikian, dalam arena ini penuh persaingan antar agen untuk memperoleh pasien. Bahkan para agen melakukan bisnis yang bertentangan dengan etika kedokteran untuk meraup keuntungan sebesar-besarnya. Hal ini disebabkan oleh habitus para agen bahwa ketenaran dan kehormatan hanya dapat diperoleh dengan mengumpulkan uang dan harta sebanyak-banyaknya.

Novel Taman Api menggambarkan bentuk habitus atau cara pandang seseorang dalam menentukan tindakan tokoh. Habitus para tokoh cerita terus bergerak dari waktu ke waktu. Pergerakan itu diakibatkan oleh pengalaman, didikan, atau bahkan pergaulan.

Perubahan dan pergerakan habitus ini berlangsung terusmenerus sehingga dapat menempatkan seseorang menjadi bagian dari sebuah arena. Namun, terkadang perubahan-perubahan habitus ini berlangsung secara tidak rasional sehingga terjadi pemaksaan dan tindakan kekerasan hingga upaya diskriminasi dari beberapa kaum yang secara sengaja dilakukan untuk membuat kaum lain merasa termarjinalkan.

Arena dalam novel Taman Api dibagi tiga. Pertama, arena kedokteran. Dalam arena ini setiap agen dihormati, dianggap orang berkelas. Namun di balik itu semua, penampilan sebagai kelompok dominan tidak mencerminkan akhlak yang baik. Hal ini karena habitus agen-agen ini dikotori oleh keinginan mendapatkan pendapatan yang besar tetapi dengan cara yang tidak benar. Kedua, arena bisnis. Dalam arena ini setiap agen berupaya menjalankan fungsi dengan sebaik-baiknya agar jaringan yang dibangun tetap bertahan untuk kepentingan bersama yaitu saling menguntungkan. Namun demikian, dalam arena ini agen lain dikorbankan yaitu para waria. Ketiga, arena waria. Dalam arena ini, setiap agen dianggap perusak tatanan moralitas, dan sering menjadi sasaran kekerasan penguasa yang disimbolkan oleh petugas Satpol Pamong Praja. Habitus penguasa telah terbentuk dengan sebuah stigma bahwa kaum waria adalah penyebab rusaknya moral bangsa, waria adalah sumber penyebaran HIV AIDS sehingga harus dimusnahkan. 
DAFTAR PUSTAKA

Bourdieu, Pierre. 2015 (cetakan ketiga). Pierre Bourdieu. Arena Produksi Kultural Sebuah Kajian Sosiologi Budaya (Diterjemahkan oleh Yudi Santoso) Bantul: Kreasi Wacana.

Creswell, John W. 2014. Penelitian Kualitatif dan Desain Riset. Memilih di antara lima pendekatan. (alih bahasa oleh Ahmad Lintang Lazuardi).Yogyakarta: Pustaka Pelajar.

Fashri, Fauzi. 2014. Pierre Boudieu. Menyingkap Kuasa Simbol. Yogyakarta: Jalasutra.
Moleong, Lexy J. 2008. Metodologi Penelitian Kualitatif. Bandung: PT.Remaja Rosdakarya.

Nurgiyantoro, Burhan. 2010. Teori Pengkajian Fiksi. Yogyakarta: Gajah Mada University Press

Rahardjo, Yonathan. 2011. Taman Api. Jakarta: Pustaka Alvabet.

Wattimena, Reza A.A. 2012. Berpikir Kritis bersama Pierre Bourdieu. http://rumahfilsafat.com/2012/04/ 14/sosiologi-kritis-dan-sosiologireflektif-pemikiran-pierrebourdieu/ Diakses tanggal 19 September 2015. 